\title{
Delineation and Characterization of Potential Groundwater Aquifer
}

\author{
[HARYATI AWANG and NORLIZAWATI MANSOR]
}

\begin{abstract}
Groundwater is a primary source of fresh water in this tropical region. There has been a growing demand for fresh water for various purposes, such as domestic, agricultural, and industrial uses. In order to meet the demand, the delineation of potential groundwater zones is essential. Electrical resistivity method is particularly suitable for groundwater studies because soil physical properties such as moisture content and grain size characteristic can be correlated to resistivity values. The resistivity technique is essentially concerned with the measurement of electrical resistivity of subsurface materials, which preferentially provides information on the different geological layers, structures and the associated occurrence of groundwater. A 2-D electrical resistivity imaging method was employed in this survey work where three (3) resistivity lines were laid. The results of resistivity survey were presented in images showing the subsurface profiles under the survey lines. The result had been interpreted to describe the subsurface based on resistivity values recorded. From this resistivity results the possible aquifer and potential tube well location were successfully identified. Hence by obtaining this result predrilling is avoidable. As a consequence the time and cost were saved due to the unnecessary mobilisation and operation of bulky site investigation machinery. Soil samples from locations of borehole drilling were collected for soil characterisation. The results from geotechnical laboratory tests strongly indicated the groundwater aquifer moisture content and grain size characters.
\end{abstract}

Keywords - resistivity, groundwater, soil characterization, tropical region, Selangor

\section{Introduction}

Groundwater is that part of precipitation that infiltrates through the soil to the water table. The unsaturated material above the water table contains air and water in the spaces between the rock particles and supports vegetation. In the saturated zone below the water table, groundwater fills in the spaces between rock particles and within bedrock fractures. Groundwater is a primary source of fresh water in this region. There has been a growing demand for fresh water for various

Haryati Awang, $\mathrm{PhD}$,

Senior Lecturer

Faculty of Civil Engineering

Universiti Teknologi MARA

Shah Alam, MALAYSIA

Norlizawati Mansor

Post-graduate Student

Faculty of Civil Engineering

Universiti Teknologi MARA

Shah Alam, MALAYSIA purposes, such as domestic, agricultural and industrial use. In order to meet the demand, the delineation of potential groundwater zones is essential. There have been several methods such as geophysical and geological methods to delineate groundwater potential zones. Since the study area is developing industrial and factory production is springing up, the study therefore, seeks to provide good potable water for human and industrial use. Hence knowing the best possible location for sinking borehole in order to access the quantity and quality of ground water supply becomes very necessary.

Conventional geotechnical exploration equipment used for site investigation consisted of big, heavy and bulky machine such as rotary wash boring, cone penetration test, etc. Nowadays, construction projects are mostly carried out on sites with difficult accessibility such as in rural and mountainous area due to the accent on land use other constraints. As a consequence, the time and cost of the project was affected due to the mobilization and operation of those bulky machines. However, current development of alternative exploration techniques from another discipline such as geophysical method is proving to be successful and worthwhile tools that are applicable for most of geotechnical investigation works. One of the geophysical methods is electrical resistivity imaging technique which is particularly suitable for groundwater studies because hydrogeological properties such as porosity and permeability can be correlated to electrical resistivity values. The geo-electrical techniques are essentially concerned with the measurement of electrical resistivity of subsurface materials, which preferentially provides information on the different geological layers, structures and the associated occurrence of groundwater [1]. Although various geophysical method techniques are available, electrical resistivity is a popular method because of its low cost, simple operation, as between the weathered overburden and the bedrock [2].

This study is conducted with the following main objectives which are to determine the groundwater existence by using electrical resistivity method, to verify the results given by resistivity measurement for delineation of groundwater potential zones using drilling method and to correlate the georesistivity value with physical properties of geo-materials by geotechnical laboratory test.

In this study a geophysical survey works has been conducted for groundwater detection using electrical resistivity method at Section 26, Shah Alam, Selangor. The purpose of this survey is to profile the subsurface condition at the above said area and to locate the possible ground water aquifer. A 2-D electrical resistivity imaging method was employed in this survey work where three (3) resistivity lines 
were laid. Alignment of resistivity lines at the study area as illustrated in Figure 1.

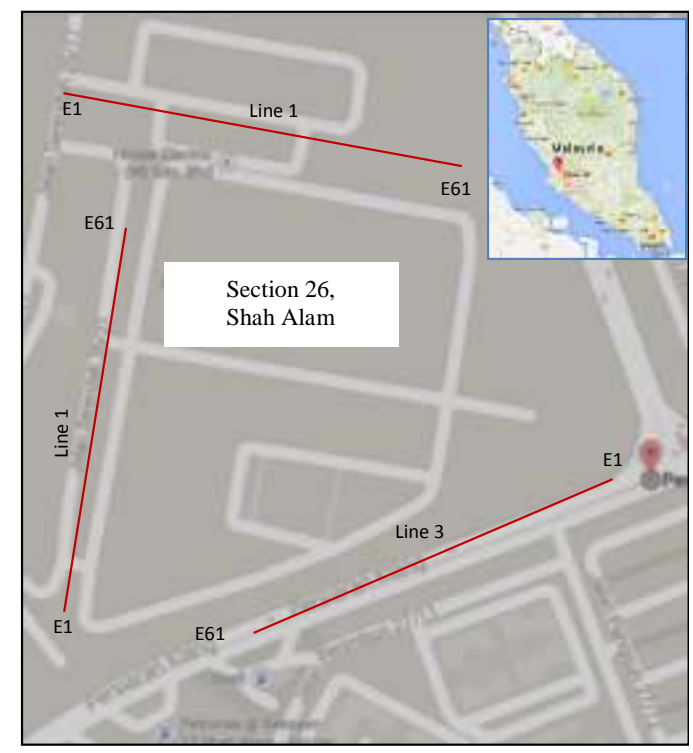

Figure 1: Location map of study area and alignment of resistivity survey lines

\section{Methodology}

\section{A. $\quad$ Electrical Resistivity Survey}

The resistivity lines were set out along the proposed alignment. The topographic profile of each resistivity line has been considered as flat level. Electrical Resistivity Imaging test was carried out with a multi-electrode resistivity meter system. A number of 61 electrodes were pinned into ground in a straight line with equal spacing. A computer-controlled system was then used to automatically select the active electrodes for each measure.

Array protocol (electrode arrangement) selected with the ABEM SAS4000 system is Schlumberger Array (Schlumberger Long and Schlumberger Short). The data collected in the survey is then converted to image using software. As the connections of lines completed and Terrameter were set up, all data was automatically recorded by the Terrameter SAS 4000 and LUND Imaging System and the data was saved in the Terrameter main unit before transferring to computer. The data collected in the survey is then converted to image using software. The resistivity data has been processed with RES2DINV software, a computer program, to automatically determine a two-dimensional (2D) resistivity model for the subsurface for the data obtained. The inverse model resistivity sections were presented together with geological interpretation and other data.

\section{B. Soil Sampling and Characterizations Tests}

After potential tube well location were identified based on the results of resistivity three (3) disturbed soil samples were collected from locations at zone A of survey line 1 , zone B of Survey Line 2 and zone $\mathrm{C}$ of Survey Line 3 as in Figure 2. The soil samples were taken to the Soil Laboratory of Universiti Teknologi MARA for moisture content and sieve analysis tests. Disturbed soil samples were taken from borehole of proposed aquifer location upon drilling works as in Figure 3 at the depth of $60 \mathrm{~m}$ to $70 \mathrm{~m}$ from the surface.

Experimental works were mainly conducted in laboratory, where the tests were performed accordance with Bristh Standard BS 1377-2: 1990. The Basic Properties Test was conducted to determine the physical properties of tested soil which are; Particle Size Distribution Test and Moisture Content Test. Sieve analysis test was carried out to determine the classification of the soil by the grain-size analysis. In this study, dry sieving method was used to classify the soils. The procedure of this test was conducted based on BS 1377: Part 2: 1990.

\section{Results and Discussions}

Results of the resistivity survey along the proposed alignment were presented in images as illustrated in Figure 2 Results of moisture content and particle size distribution described the characterizations of the soil samples that were taken from the potential aquifer locations. The image of each line was interpreted to describe the subsurface material by referring to [3] .The range of resistivity value is represents by each color as indicated at the bottom of the image. In principles low resistivity value indicates that the sub surface material easily allow electric current to flow through. As for example, water and soil with high moisture content have low resistivity value. Meanwhile high resistivity value indicates that the sub surface material retard or hardly allow electric current to flow through. Rocks, dry sand, dry clay, compacted soil and air (void) have high resistivity value or relatively high to the surroundings. Resistivity value that less than $10 \Omega \mathrm{m}$ is interpreted as saturated zone (clay/high moisture). Resistivity value between $10 \Omega \mathrm{m}$ to $100 \Omega \mathrm{m}$ is interpreted as sand with moisture and resistivity value of more than $100 \Omega \mathrm{m}$ is interpreted as hard material or rock [4].

\section{A. Electrical Resistivity Images and Interpretations}

The electrical resistivity result as given in Figure 2 displays cross section profiles of $400 \mathrm{~m}$ survey length with a maximum depth $70 \mathrm{~m}$. These profiles were produced with the $5 \mathrm{~m}$ electrode spacing adopted in order to determine possible aquifer locations. The images were interpreted and described by line by line basis. 


\section{Line 1}

The resistivity image of Line 1 in Figure 2a shows that aquifer possibly can be found at location around $175 \mathrm{~m}$ from electrode 1 (E1) position. The profile displayed that the top layer of the subsurface is mostly covered by high resistivity zone $(>100 \Omega \mathrm{m})$ indicated by red or dark red color which is interpreted as hard material. Lowest resistivity value $(<3 \Omega \mathrm{m})$ indicated by dark blue color significantly exist at second layer (middle layer of the section) interpreted as clay. The resistivity value around $50 \Omega \mathrm{m}$ in greenish color is interpreted as wet sand and existed at the bottom of profile.

\section{Line 2}

The resistivity image in Figure $2 b$ shows a subsurface profile along $400 \mathrm{~m}$ of resistivity survey Line 2 . The image shows that aquifer possibly located at $145 \mathrm{~m}$ from E1 at the depth of more than $70 \mathrm{~m}$. The profile displayed that the $20 \mathrm{~m}$ top layer of the subsurface is mostly covered by high resistivity zone $(>100 \Omega \mathrm{m})$ indicated by yellow to dark red color which is interpreted as hard material. Lowest resistivity value $(<3 \Omega \mathrm{m})$ indicated by dark blue color significantly exist at second layer located at $20 \mathrm{~m}$ to $50 \mathrm{~m}$ depth (middle layer of the section) interpreted as saturated zone. The resistivity value around $50 \Omega \mathrm{m}$ in greenish color is interpreted as wet sand was found scattered between $5 \mathrm{~m}$ to $60 \mathrm{~m}$ of the profile. The profile shows that the zone of aquifer consists of saturated sand are possibly located at bottom depth or more than $70 \mathrm{~m}$ from the surface. It was predicted that the greenish colour of profile representing wet sand that start from $30 \mathrm{~m}$ from the surface possibly further extending until $70 \mathrm{~m}$ below the soil layer.

\section{Line 3}

The resistivity image in Figure 2c shows a subsurface profile along $400 \mathrm{~m}$ of resistivity survey line 3 . The image shows that at the top layer of the subsurface, is mostly covered by high resistivity zone $(>100 \Omega \mathrm{m})$ indicated by red or dark red color which is interpreted as hard material. Lowest resistivity value $(<3 \Omega \mathrm{m})$ indicated by dark blue colour significantly exist at second layer (middle layer of the section) interpreted as clay. The resistivity value around $50 \Omega \mathrm{m}$ in greenish colour is interpreted as wet sand was found at the bottom of profile. It can be predicted as zone of aquifer that consists of saturated sand is possibly located at $200 \mathrm{~m}$ from E1 at the depth of more than $60 \mathrm{~m}$ from the surface.

Note that the colour varieties of the image represent the different resistivity value as indicated by the colour chart at the bottom of the image. In summary all the images showed three different zones of resistivity which high resistivity zone which is more than $100 \Omega \mathrm{m}$ interpreted as hard material and low resistivity zone which is less than $3 \Omega \mathrm{m}$ interpreted as clay. Intermediate resistivity zone which the values is around $50 \Omega \mathrm{m}$ interpreted as wet sand where aquifer or groundwater potential locations were identified.

\section{B. Soil Characterizations}

In this study, after the possible ground water aquifer has been identified, drilling works had been proceeded at the proposed aquifer locations and groundwater was successfully detected. Soil samples from locations of borehole drilling at point A, B and $\mathrm{C}$ (Figure 2) were collected immediately for moisture content and particle size distribution test. Result from laboratory geotechnical tests were compared with the result obtained from the electrical resistivity method, analyzed and the findings of the test were discussed.

Result of soil tests for the soil samples collected at point A, $\mathrm{B}$ and $\mathrm{C}$ is displayed in Table 1. It was found that the soil at point $\mathrm{A}$ is consisting of $60.93 \%$ sand, $39.01 \%$ gravel and only $0.06 \%$ silt. Meanwhile at point $\mathrm{B}$, the soil is consisting of $74.76 \%$ sand, $24.90 \%$ gravel and only $0.33 \%$ silt. At Point C, the soil is consisting of $79.11 \%$ sand, $20.80 \%$ gravel and only $0.09 \%$ silt. Moisture content at point A, B and C were recorded as $40.0 \%, 39.25 \%$ and $56.0 \%$ respectively. Hence, this study was demonstrate that locations of potential aquifer consists of high moisture content and consist of higher quantity of coarse soil and lower quantity of fine soil .

TABLE I. PARTICLE SIZE DISTRIBUTION AND MOISTURE CONTENT AT AQUIFER

\begin{tabular}{|c|c|c|c|}
\hline $\begin{array}{c}\text { Soil } \\
\text { sample }\end{array}$ & $\begin{array}{c}\text { Particle } \\
\text { size }\end{array}$ & $\begin{array}{c}\text { Quantity } \\
(\%)\end{array}$ & $\begin{array}{c}\text { Moisture } \\
\text { Content (\%) }\end{array}$ \\
\hline & Gravel & 39.01 & \\
Sample A & Sand & 60.93 & 40.00 \\
& Silt & 0.06 & \\
& Clay & - & \\
\hline & Gravel & 24.90 & \\
Sample B & Sand & 74.76 & 39.25 \\
& Silt & 0.33 & \\
& Clay & - & \\
\hline & Gravel & 20.80 & \\
Sample C & Sand & 79.11 & 56.00 \\
& Silt & 0.09 & \\
& Clay & - & \\
\hline
\end{tabular}

\section{Iv. Conclusions}

An electrical resistivity imaging study has been carried out to delineate groundwater existence over industrial area in Shah Alam district of Selangor, a state of Malaysia. The locations of groundwater potential was successfully identified where verification of the groundwater zones were conducted using drilling method. Characterizations of geo-materials by geotechnical laboratory test showed that the groundwater aquafers consist of coarse grain material where the resistivity value is approximately less than $100 \Omega \mathrm{m}$. 
Proc. of the Intl. Conf. on Advances in Civil, Structural and Mechanical Engineering - ACSM 2015.

Copyright $(\odot$ Institute of Research Engineers and Doctors, USA .All rights reserved.

ISBN: 978-1-63248-039-2 doi: 10.15224/ 978-1-63248-039-2-22

a. Line 1

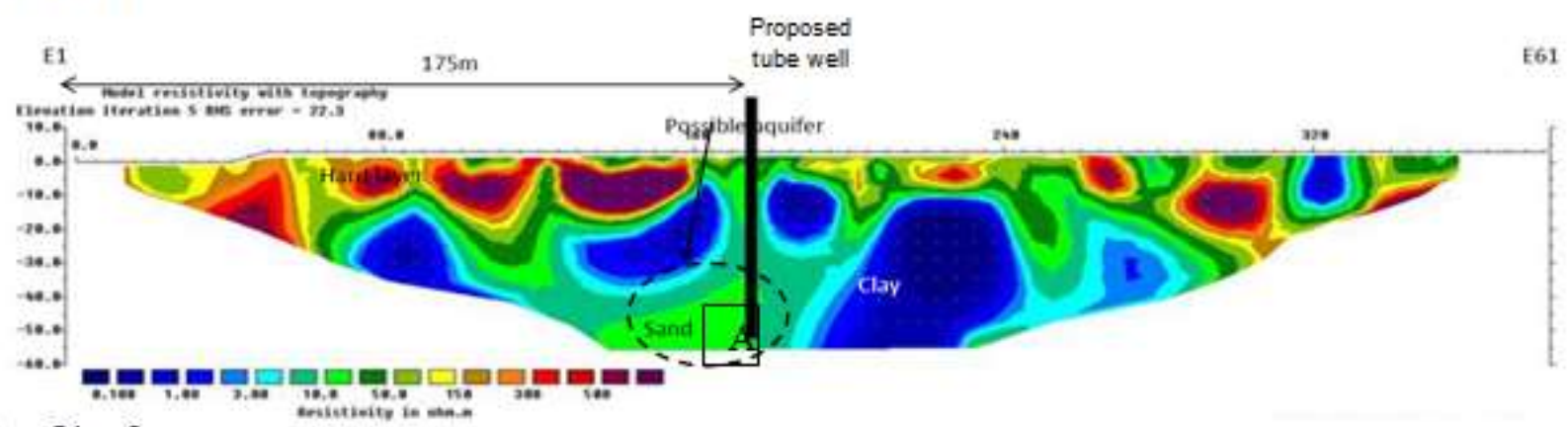

b. Line 2

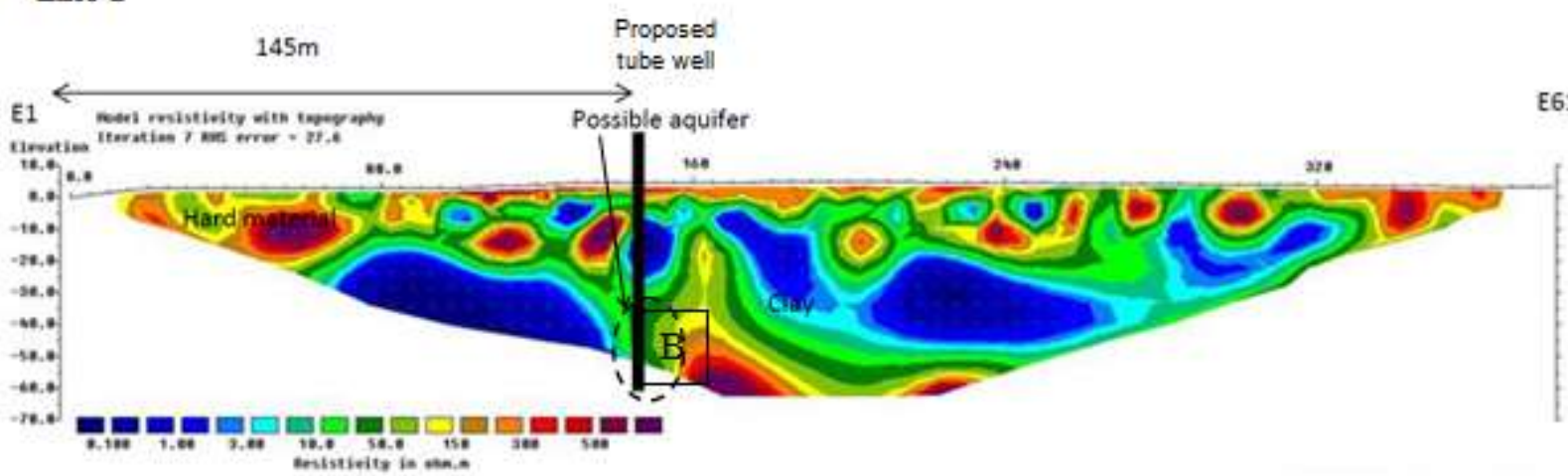

c. Line 3

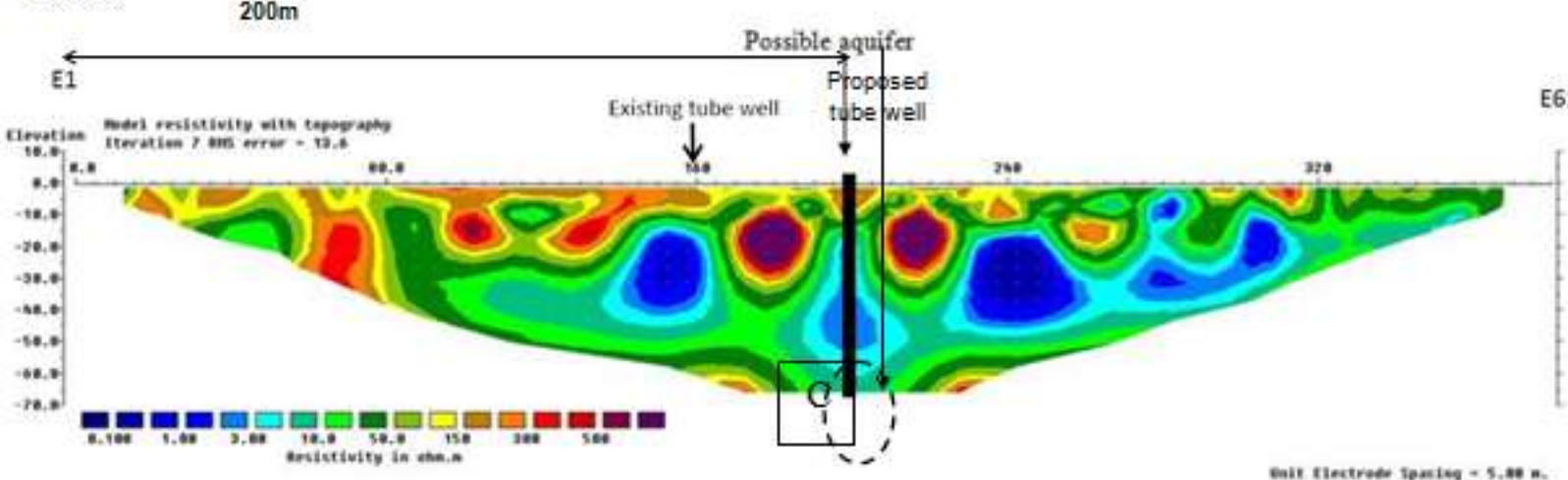

Figure 2: Resisitivity images of Line 1, Line 2 and Line 3 with potential aquifer, proposed tube well drilling and soil sampling locations (A,B and C)
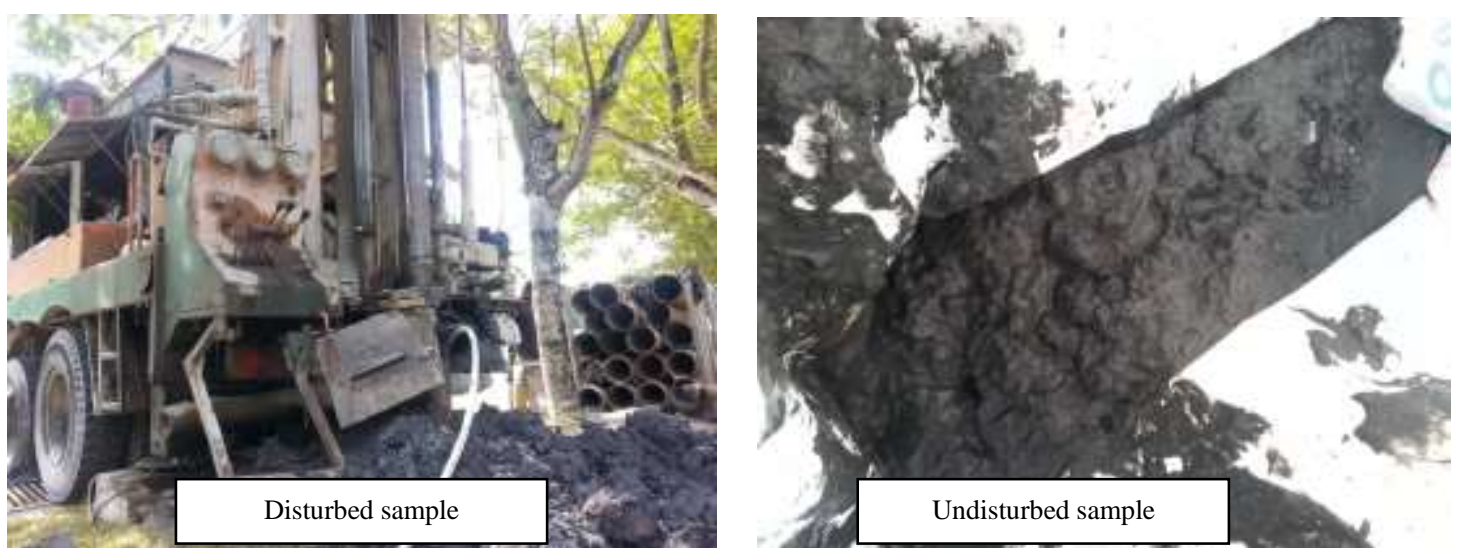

Figure 3: Disturbed sample from drilling works and undisturbed sample from required depths. 
Proc. of the Intl. Conf. on Advances in Civil, Structural and Mechanical Engineering - ACSM 2015.

Copyright $\odot$ Institute of Research Engineers and Doctors, USA .All rights reserved.

ISBN: 978-1-63248-039-2 doi: 10.15224/ 978-1-63248-039-2-22

\section{References}

[1] R.A. Van Overmeeren. "Aquifer boundaries Explored by Geoelectrical Measurement in the Coastal Plain of Yamen: A Case of Equvalence". Geophysics, pp. 38-48, Vol.54 (1), 1989.

[2] W.M. Telford, and R.F.Sheriff, "Applied Geophysics" Cambridge University Press. 1984.

[3] M.H.Loke, J.W. Lane Jr.,. "Inversion of data from electrical resistivity imaging surveys in water-covered areas". Exploration Geophysics. Vol. 35 (4), pp. 266-271. 2004

[4] J.A.Doolittle, K.A. Sudduth, N.R.Kitchen, S.J.Indorante. “ Estimating depths to claypans using electromagnetic induction methods" Journal of Soil and Water Conservation, Vol.49, pp. 572-575. 1994. 